\title{
Identification by molecular diagnosis of mosaic Turner's syndrome in an obligate carrier female for fragile $\mathrm{X}$ syndrome
}

Unidad de Genética

Humana, Santo

Hospital Civil de

Bilbao, Avenida

Montevideo 18, 48013

Bilbao, Spain

M I Tejada

M Molina

INSERM U73, Paris,

France

E Mornet

A Boue

Unitat de Genética Molecular, Hospital

de la Santa Creu i

Sant Pau, Barcelona,

Spain

E Tizzano

M Baiget

Correspondence to

Dr Tejada

Received 15 February 1993 Revised version accepted for
publication 6 July 1993

\author{
M I Tejada, E Mornet, E Tizzano, M Molina, M Baiget, A Boue
}

\begin{abstract}
A case of mosaic Turner's syndrome with a 45,X/46,XX/47,XXX karyotype, who was also a fragile $\mathbf{X}$ obligate carrier as the mother of an affected boy, was identified by molecular diagnosis. Complete haplotyping and direct DNA analysis showed that the $X$ chromosome in all metaphases was the normal $X$. At the age of 57 , she is mentally normal. Her external appearance was typical of Turner's syndrome.

This report shows that molecular studies in conjunction with cytogenetic analysis can help in the clinical diagnosis of a rare case and can show the uniqueness of a case such as the one here described.
\end{abstract}

( $(\mathcal{F}$ Med Genet 1994;31:76-78)
1

III
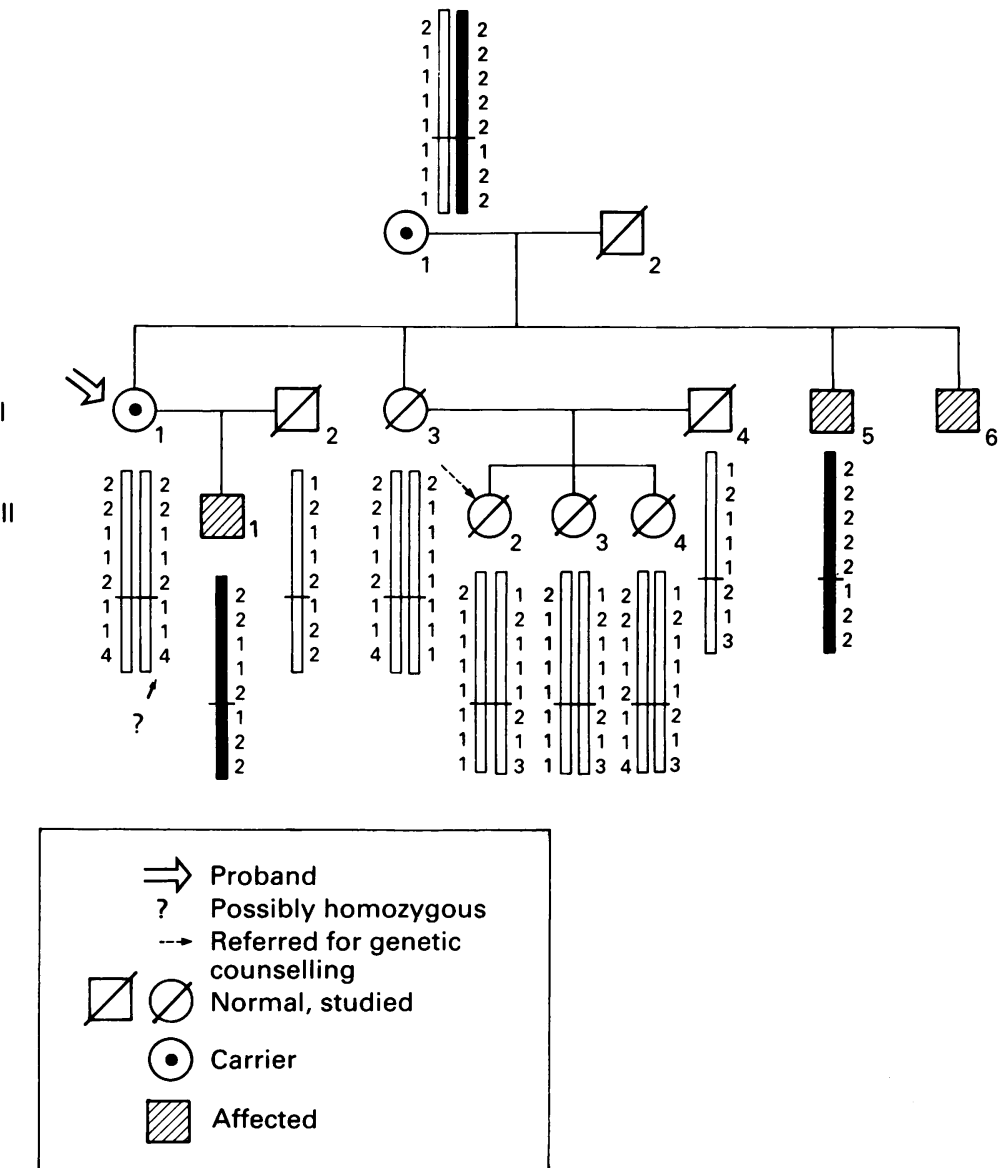

Figure 1 Pedigree of the family with the haplotypes of the fra $(X)$ region. Proximal to the centromere: FIX, Cx55.7, 55E, 4D8, and RNI. Distal, UG.2, 1A1, and St.14.
It has recently been shown that the detection of chromosomal mosaicism can be substantially enhanced if at least two kinds of tissue and a greater number of cells are examined. Only 20 to $25 \%$ of women with Turner's syndrome are non-mosaic $45, \mathrm{X}$, whereas twothirds of patients overall exhibit chromosomal mosaicism. ${ }^{1}$ In general, patients with sex chromosome mosaicism exhibit milder signs of the typical phenotype, so that fertility in these women has been reported. ${ }^{2}$

Patients with Turner's syndrome, as well as hemizygous males, can be affected by $\mathrm{X}$ linked disease owing to the lack of one $\mathrm{X}$ chromosome. Hence, cases of Turner's syndrome and Duchenne muscular dystrophy (DMD) have been described. ${ }^{3}$ The case of a DMD carrier detected by molecular diagnosis in a female with mosaic Turner's syndrome was reported two years ago. ${ }^{4}$

The fragile $X$ syndrome $(\operatorname{fra}(X))$ is the most frequent cause of inherited mental retardation, with an incidence of about 1 in 1500 males and 1 in 2500 females. $^{5}$ The case we report here was found in a family referred to us for $\operatorname{fra}(\mathrm{X})$ examination owing to mental retardation in two male members. To our knowledge it is the first case reported of a woman who had mosaic Turner's syndrome, who was a fra(X) carrier, and who was the mother of an affected male.

\section{Case report}

A woman (III.2, fig 1) was referred to us five years ago for genetic counselling because she had an uncle and a cousin who were mentally retarded. Her family lives a long way away so they could not be examined. Photographs of the family suggested fragile $X$ syndrome, so we requested by mail samples of blood from the two retarded males. The karyotypes showed $33 \%$ (II.5) and $47 \%$ (III.1) of fra(X) cells. The karyotype of the index case proved normal.

Since not all fragile $\mathrm{X}$ carriers show cytogenetic expression, we wished to confirm by molecular diagnosis that she was not a carrier for $\mathrm{fra}(\mathrm{X})$. Blood samples were obtained by mail from the entire family, and complete haplotyping was carried out with eight probes (fig 1). We were then able to determine that our index case (III.2) had not inherited the $\mathrm{fra}(\mathrm{X})$ mutation.

Surprisingly, the DNA sample taken from patient II.1 appeared to be homozygous for all the polymorphic markers studied. The haplotype did not seem to be of maternal origin. In addition, the bands exhibited the characteristic 

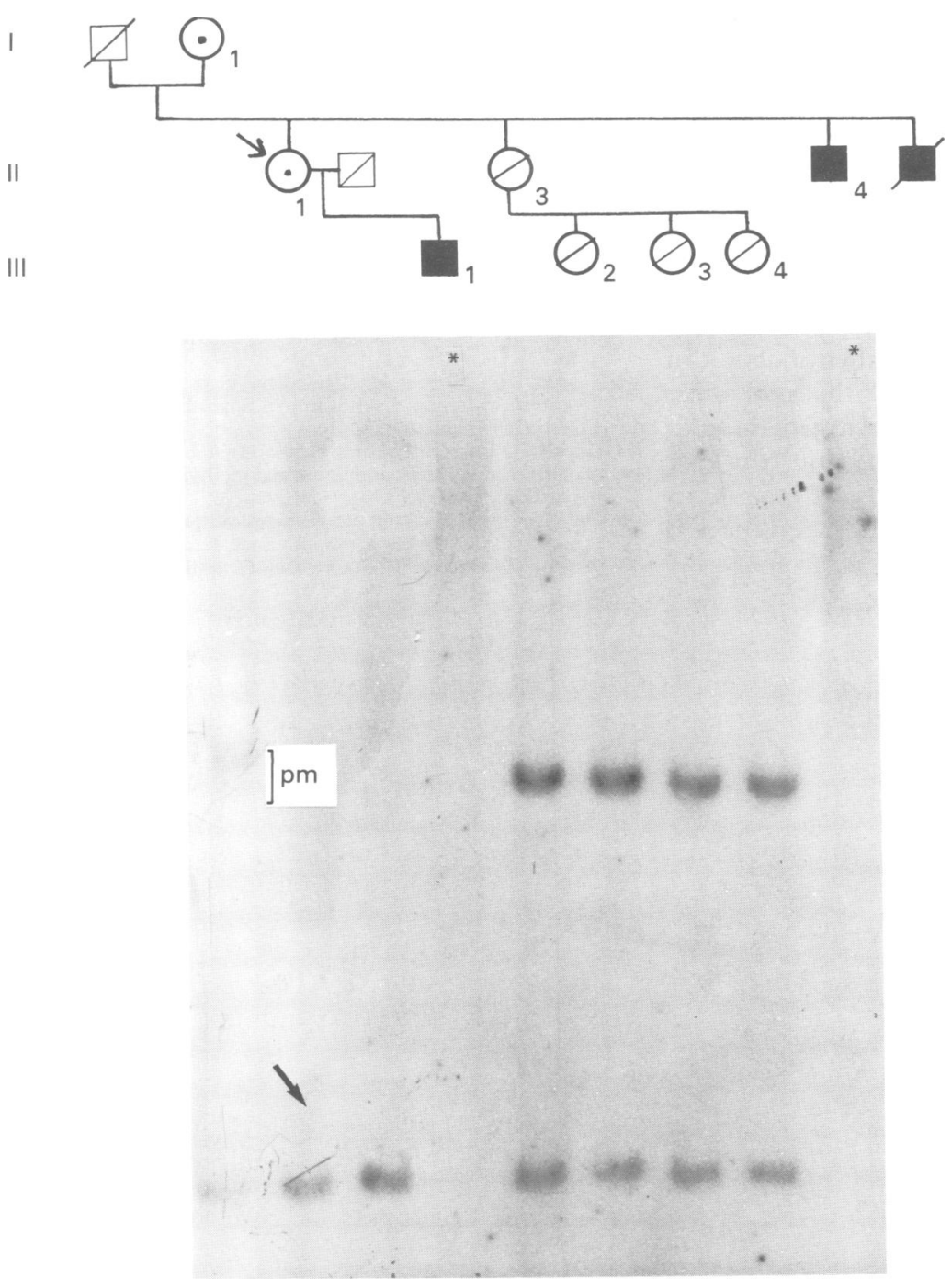

Figure 2 Southern blot analysis with the DNA probe StB12.3 (EcoRI-EagI). * = smear in affected males. An arrow marks the unique restriction fragment in the index case $(I I \cdot 1)$ corresponding to the normal $X$. pm=premutation in the grandmother.

\section{$\|\cdot 4\| \cdot 3\|\cdot 1\| \cdot 2 \| \cdot 1 \mid \cdot 1$}

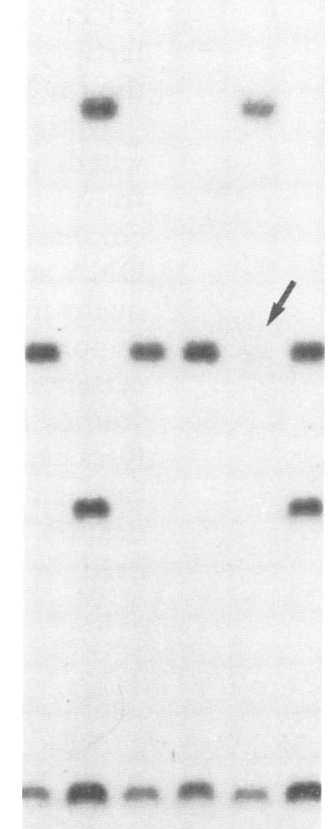

Figure 3 Southern blot analysis with Msp + St14. An arrow marks the very low intensity allele corresponding to the maternal X chromosome involved in the Turner mosaic.

cluded that the $\mathrm{X}$ chromosome present in all cells is the normal $\mathrm{X}$ from the father, whereas the $\operatorname{fra}(\mathrm{X})$ chromosome from the mother is present only in $16 \cdot 2 \%$ of the cells.

\section{Discussion}

Mosaicism of the type $45, \mathrm{X} / 46, \mathrm{XX} / 47, \mathrm{XXX}$ arises from non-disjunction in a chromosomally normal female during mitosis after fertilisation. In general, mosaic Turner's syndrome shows milder signs than other cases of Turner's syndrome with $45, \mathrm{X}$ only. When the proportion of $45, \mathrm{X}$ cells increases, symptoms of Turner's syndrome begin to appear. Our case II.1, having $83.8 \%$ of $45, \mathrm{X}$ cells, is phenotypically typical of Turner's syndrome except for fertility. The proportion of 45,X cells increases in older women ${ }^{8}$ because, in general, mitotic non-disjunction, as well as other chromosome aberrations, increases in older persons, who show more aberrant cells than younger ones. We thus felt that our patient, karyotyped at 57 years, should have had fewer abnormal cells before. Moreover, the karyotype was performed on a blood sample and blood cells are different in origin from gonadal ones, which are of extra-embryonic origin. Hence if there were more normal cells in gonadal tissue, this could explain this woman's 14 year fertility. Nielsen et al reported 23 similar cases of mosaic Turner's syndrome in which there were 56 pregnancies.

Fertility might have given problems for this patient because she was also a carrier for fra $(X)$ syndrome. Direct molecular diagnosis and haplotyping showed that the $\mathrm{X}$ chromosome carrying the $\mathrm{fra}(\mathrm{X})$ mutation was the one involved in the Turner mosaicism, or rather the one lost in many cells. We thus consider that there was a process of natural selection 
working against the abnormal $\mathrm{X}$, and that this selection, being incomplete, failed to preclude fertility and made possible the transmission of the $\mathrm{fra}(\mathrm{X})$ to the only son.

Initially the aim of the study was to find out whether our index case (III.2) was a carrier for $\mathrm{fra}(\mathrm{X})$ syndrome. The finding we report here emphasizes, however, that although direct DNA analysis of fra $(X)$ syndrome is now frequent in laboratories, cytogenetics still has an important role to play in the identification of certain cases. Our conclusion is that molecular studies in conjunction with cytogenetic analyses can enhance the clinical diagnosis of rare cases and furthermore can facilitate the identification of unique cases like the one reported here.
1 Held KR, Kerber S, Kaminsky E, et al. Mosaicism in 45,X Turner syndrome: does survival in early pregnancy depend on the presence of two sex chromosomes? Hum Genet 1992;88:288-94.

2 Nielsen J, Sillesen K, Hansen KB. Fertility in women with Turner's syndrome. Case report and review of literature. Br f Obstet Gynaecol 1979;86:833-5.

3 Bortolini ER, Da Silva DM, Chequer RS, Vianna-Morgante AM, Zatz M. Duchenne muscular dystrophy in a girl with a 45,X/46,XX/47,XXX chromosome constitution. $A m \mathcal{F}$ Med Genet 1986;25:239-43.

4 Baiget M, Tizzano E, Volpini V, Del Rio E, Perez-Vidal T, Gallano P. DMD carrier detection in a female with mosaic Turner's syndrome. F Med Genet 1991;28:209-10.

5 Sutherland GR. The enigma of the fragile X chromosome. Trends Genet 1985;1:108-12.

6 Tejada MI, Mornet E, Biancalana V, et al. Direct DNA analysis of fragile $\mathrm{X}$ syndrome in Spanish pedigrees. $A m \mathcal{F}$ Med Genet 1992;43:282-90.

7 Oberlé I, Rousseau F, Heitz D, et al. Instability of a 550-base pair DNA segment and abnormal methylation in fragile $\mathrm{X}$ syndrome. Science 1991;252:1097-102.

8 Galloway SM, Buckton KE. Aneuploidy and ageing: chromosome studies on a random sample of the population using G-banding. Cytogenet Cell Genet 1978;20:78-95. 